\title{
In memory of Leonid Evtushik and Jan Kubarski
}

Josef Mikěs, Bogdan Balcerzak, and Miroslav Kurě̌ 


\title{
IN MEMORY OF LEONID EVTUSHIK AND JAN KUBARSKI
}

\author{
JOSEF MIKEŠ, BOGDAN BALCERZAK, AND MIROSLAV KUREŠ
}

For the AGMP-8 Conference in Brno, we were trying to gather experts in differential geometry and colleagues from abroad having long-term cooperation with Czech universities. Among them were two professors, Leonid Evtushik and Jan Kubarski, both good friends of Czech mathematicians and the Czech Republic. They had even visited Brno before. We also planned for further cooperation with them, Leonid was to continue research cooperation with Josef Mikeš and Jan was to attend our Spring School of Invariant Theory in Písek (April 2013). Unfortunately, none of this had happened as both excellent mathematicians and genuine friends died unexpectedly.

The following lines in their memory should remind you of their great importance for mathematics - we think it notable that Brno was the venue of their last conference and, thus, their participation will stay forever in our memories.

\section{LEONID E. EVTUSHIK, 1931-2013}

We lost Leonid Evgenyevich Evtushik on 15th February 2013. We will miss this great scientist, honorary professor of the Lomonosov Moscow State University, and excellent man for a long time.

L. E. Evtushik was born on 25th May 1931 in Priluky in the centre of the Chernigov region in Ukraine. In 1949 he graduated there from the secondary school and passed entrance exam to the Faculty of Mechanics and Mathematics of the Lomonosov Moscow State University. Then, his scientific life was connected with this university:

In 1954, he received a diploma with distinction and began studying for a $\mathrm{PhD}$ degree at the Faculty of Mechanics and Mathematics. Mr. Evtushik also obtained the scientific degree of "Doctor of Science" being appointed professor at the Faculty of Mechanics and Mathematics of MSU. His scientific interests were formed by such excellent geometers as S.P. Finnikov, G.F. Laptev (his PhD supervisor), A.M. Vasilev, founder of the MSU oldest scientific seminar on classical and modern differential geometry; Prof. Evtushik actively participated in this seminar and gradually became their successor passing on their scientific tradition. He was interested especially in the theory of higher-order differential geometric structures, which describes invariant structures in mathematical analysis such as differential equations, operators, Lagrangians, Hamiltonians, etc. His scientific work was devoted to perfecting the 
Cartan-Laptev method based on a theoretic categorical approach, which agrees well with the differential-algebraic apparatus of jets and external algebras.

In recent years, the main activities of L. E. Evtushik have concentrated on a largescale general geometric problem - structuring and inclusive modern description of a generic Cartan-Laptev method and mission-critical applications to the invariant structures of analysis and geometry of arbitrarily high orders on smooth manifolds.

The main results of L. Evtushik are the following:

1. For multidimensional Lagrangians of the second order an invariant connection of the Cartan type was constructed in a special principal bundle with the complete system of structural equations and corresponding invariants,

2. A completely new detailed theory was developed of higher-order non-linear connections in an arbitrary principal and associated bundles; this theory has very interesting and promising specification for a natural category of principal bundles frame bundles of higher orders on smooth manifolds,

3. On this basis, the most natural approach was developed to constructing the geometry of higher-order ordinary differential equations and its implementation for the third, fourth and fifth orders,

4. A method of constructing an invariant form and structural equations of pseudogroups of transformations was given; it is more natural than the Cartan one,

5. In the monograph Theory of differential geometric structures on smooth manifolds (Problems of Geometry, 9, 199X), the current construction of the Cartan-Laptev method is given as a universal methodological platform for 1., 2., 3., 4.; this method is presented as an apparatus of structural differential forms and structural equations of differential geometric structures in their most general sense based on the theory of fiber bundles and calculus of invariant differential forms and jets of maps, as well as the theoretic categorical approach,

6. It was shown that a general theory of Lie differentiation in its invariant form is automatically built into the theory of connections and its structural equations; it represents a fruitful approach to the description of the invariant Hamiltonian systems for Lagrangians of higher order.

Besides L. E.Evtushik's individual research, we should also mention his scientific and organizational work of the whole scientific school, referred to as the CartanLaptev school, for the organization and functioning of which he was fully responsible. He also organized a large international conference at MSU dedicated to the 90th anniversary of L. F. Laptev, which was the beginning of regular Laptev Readings, held in various geometric centers of the country, with the participation of geometries from Italy, Yugoslavia, Hungary, the Czech Republic, Poland, Norway, and USA. The scientific achievements of L. E. Evtushik won great acclaim at the international congress on the occasion of the 200th anniversary of the birth of N. I. Lobachevsky, and in 2009, he was awarded the Anasilaus medal in Italy. His scientific activities were 
supported by many grants and recalled at international mathematical congresses, geometric conferences (Zürich, Berlin, Vienna, Budapest, Brno, Olomouc, Prague, Belgrade, Warsaw) and numerous geometrical conferences in the country. He published over 100 publications on this topic and more than $20 \mathrm{PhD}$ students defended their dissertations.

The teaching activities of Prof. Evtushik were no less diverse: a long-term chairman of the Methodical Commission of the All Union School of Mathematics at Moscow State University, a member of the Dissertation Council of the MSU and Moscow State Pedagogical University, part-time head of the department of computer science at the University of Tver and professor at the Penza Pedagogical University, a member of the Committee on Education and science of the State Duma of Russia, diverse teaching activities in geometry and mathematical analysis, supervision of $\mathrm{PhD}$ students. For his pedagogical gift, L. E. Evtushik was awarded a degree of Honorary Professor of Moscow State University.

In addition to research and teaching, Prof. Evtushik engaged in travel during large part of his life. The geography of his travels covers the entire Eurasian continent. From Spain and Portugal to China, from Norway to Sicily and Peloponnese. All the republics of the Soviet Union, from the Baltic and Ukraine to Azerbaijan and Kyrgyzstan. And of course the whole of Russia, from the mountains of Chechnya to the northern seas, from Kaliningrad (Königsberg) to Irkutsk and Vladivostok. And everywhere Leonid visited places connected with the history of mathematics and the lives of outstanding mathematicians. In Sicily, he found the tomb of Archimedes, in Norway, he travelled to places associated with Sophus Lie, in Germany, he visited the Klein memorial in Erlangen. But most of all he was attracted by places related to Elie Cartan. He visited twice the home of the outstanding mathematician in a small French town of Dolomie (near Lyon). In Russia, he went to the homes of Chebyshev, Ostrogradsky and other mathematicians, who brought glory of the national science, and of course in Kazan' where N. I. Lobachevsky created his non-Euclidean world. Professor Evtushik travelled to the home of Michail Lomonosov, the founder of Moscow University, where he spent his entire scientific life.

We have lost a great scientist and teacher and a fine man.

\section{JAN KUBARSKI, 1950-2013}

Jan Kubarski was born on 26 December 1950 in Łódź, Poland. In 1969, after completing a Secondary Technical School of Mechanical Engineering No. 4 in Łódź (class in cinematic techniques), he entered the Faculty of Mathematics, Physics and Chemistry at the Łódź University, where he studied mathematics. After obtaining his degree, Jan Kubarski began his PhD studies at the Mathematical Institute of the Polish Academy of Sciences in Warsaw, where in 1977 he defended his PhD Thesis entitled About Groupoids and Lie Algebroids (in Polish) under the supervision of Professor Włodzimierz Waliszewski. At that time Lie groupoids and Lie algebroids 
were hardly studied in Poland. It was Professor Ivan Kolář (Masaryk University, Brno) who introduced Jan Kubarski to the subject and who acted as an informal co-supervisor of the thesis. He received the habilitation degree in mathematics at the Łódź University in 1993 for his dissertation, The Chern-Weil homomorphism of regular Lie algebroids. On 21 December 2007, President of Poland Professor Lech Kaczyński conferred upon him the degree of professor of mathematical sciences.

In 1977, he started to work at the Institute of Mathematics of the Łódź University of Technology where, from 1997 until is death, he worked as an associate professor. In 2000-2002, he held the office of vice-dean for science of the Faculty of Technical Physics, Information Technology and Applied Mathematics, Łódź University of Technology.

He worked in differential geometry, with particular interest in characteristic classes in categories of Lie groupoids and Lie algebroids. The most valuable results obtained by Jan Kubarski are those that concern the primary and secondary characteristic classes, and also a paper on Bott's vanishing theorem for Lie algebroids. His habilitation thesis was devoted to the construction and research of the Chern-Weil homomorphism for regular Lie algebroids. Some of his works are devoted to differential spaces and foliations with singularities in the sense of Stefan. His latest research mainly focused on the study of cyclic Čech-Hochschild bicomplexes.

Jan Kubarski published nearly 50 scientific research articles. He is the author of many reviews in Mathematical Reviews of the AMS and Zentralblatt MATH and coauthor of Encyclopedia of Mathematics, famous in Poland (Encyklopedia szkolna. Matematyka, in Polish).

He actively participated in many international conferences delivering lectures, plenary lectures, seminars and training sessions. He was a co-organizer of nine conferences in the Geometry and Topology of Manifolds cycle and conferences such as: Forum of Geometry (Warsaw, 2000), Lie Algebroids and Related Topics in Differential Geometry (Warsaw, 2000), $C^{*}$-algebras and Elliptic Theory. III (Bȩdlewo, Poland, 2009), Geometry of Manifolds and Mathematical Physics (Kraków, 2011). He participated in editing several volumes of the monograph conference proceedings in such journals as Universitatis Iagellonicae Acta Mathematica, Banach Center Publications, Central European Journal of Mathematics, and Travaux Mathématiques. He maintained scientific contacts with research centres in Poland and in the world — in particular with Masaryk University in Brno (Ivan Kolár), Moscow State University (Alexander S. Mishchenko), University of Paul Sabatier in Toulouse (Jean Pradines), National Technical University of Ukraine, "Kiev Polytechnic Institute" (Roman Kadobianski) and Marche Polytechnic University in Ancona (Nicolae Teleman). He supervised three PhD students in mathematics.

Jan Kubarski was an enthusiast of computer technology and a great fan of photography, travel, history of Poland, and ancient history. In particular, he was interested 
in the history of the beginnings of mathematics in the great civilizations of the Bronze Age and Iron Ages.

He died unexpectedly on 8th June 2013 in Łódź.

Authors' addresses

Josef Mikeš

Palacky University, Faculty of Science, Department of Algebra and Geometry, 17. listopadu 12, 77146 Olomouc, Czech Republic

E-mail address: josef.mikes@upol.cz

\section{Bogdan Balcerzak}

Institute of Mathematics, Łódź University of Technology, Wólczańska 215, 90-924 Łódź, Poland

E-mail address: bogdan.balcerzak@p.lodz.pl

Miroslav Kureš

Institute of Mathematics, Brno University of Technology, Technická 2, 61669 Brno, Czech Republic

E-mail address: kures@ fme.vutbr.cz 